\title{
Hypertrophic cardiomyopathy - screening and etiology detection
}

\author{
(i) Ivana Lukić', \\ (DIva Jurić', \\ Vjekoslav Amidžić',2, \\ (D) Kristina Selthofer- \\ Relatić', ${ }^{2 *}$ \\ 'University Hospital Centre \\ Osijek, Osijek, Croatia \\ 2University Josip Juraj \\ Strossmayer 0sijek, Faculty \\ of Medicine, Osijek, Croatia
}

RECEIVED:

February 28, 2019

ACCEPTED:

March 24, 2019

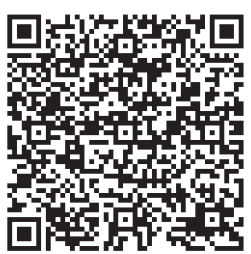

$\square$ Cardiologia Croatica 2019:14(3-4):66.
KEYWORDS: Anderson-Fabry disease, ATTR amiloydosis, genetic testing, hypertrophic cardiomyopathy, left ventricular hypertrophy.

CITATION: Cardiol Croat. 2019;14(3-4):66. | https://doi.org/10.15836/ccar2019.66

*ADDRESS FOR CORRESPONDENCE: Kristina Selthofer-Relatić, Klinički bolnički centar Osijek, J. Huttlera 4, HR31000 0sijek, Croatia. / Phone: +385-31-511-717 / E-mail: selthofer.relatic@gmail.com

ORCID: Ivana Lukić, https://orcid.org/0000-0001-9832-6700 • Iva Jurić, https://orcid.org/0000-0002-0975-3039 Kristina Selthofer-Relatić, https://orcid.org/0000-0002-9890-6489

\section{|IIIIIIIIIIIIIIIIIIIIIIIIIIIIIIIIIIIIIIIIIIIIIIIIIIIIIIIIIIIIIIIIIIIIIIIIIIIIIIIIIIIIIIIIIIIIIIIIIIIIIIIIIIIIIIIIIIIIIII}

Left ventricular hypertrophy is an adopted response to physiological and pathological stress, while hypertrophic cardiomyopathy (HCM) is defined by the presence of increased left ventricular wall thickness that is not solely explained by abnormal loading conditions. Determination of the etiology, pathophysiology and disease severity is important for the management of patients with HCM.1-4 According to latest European Cardiology Society Guidelines for $\mathrm{HCM}^{2}$, etiology in adults are $60 \%$ an autosomal dominant trait caused by mutations in cardiac sarcomere protein genes, $5-10 \%$ caused by other genetic disorders including inherited metabolic and neuromuscular diseases, chromosome abnormalities and genetic syndromes, malformation syndromes, non-genetic disorders that mimic genetic forms of the disease like amyloidosis and infiltrative diseases. In about 25-30\% of HCM etiology is still unknown.

In adults, HCM is defined by a wall thickness $\geq 15 \mathrm{~mm}$ in one or more LV myocardial segments as measured by any imaging technique. Transthoracic 2D and tissue doppler echocardiography presents tool for morphologic and hemodynamic evaluation (with additional strain analysis, contrast and transesophageal echocardiography), and cardiac MRI for assessment of cardiac morphology and myocardial tissue characteristics. Routine laboratory tests and specific testing aids the detection of HCM etiology. The majority of HCM cases are inherited autosomal dominant genetic trait with a 50\% risk of transmission to offspring. Some cases are explained by de novo mutations, sporadic cases can arise because of incomplete penetrance in a parent and by autosomal recessive inheritance. Regular genetic analysis should include the most commonly implicated sarcomere protein genes, and pedigree analysis should be provided. Annual incidence of cardiovascular death is $1-2 \%$ caused by sudden cardiac death, heart failure or thromboembolism.

HCM etiology detection is necessary because of treatment possibilities (like Anderson-Fabry disease or ATTR amyloidosis), detection of secondary causes of disease, the need for family screening and differentiating pathogenic from non-pathogenic mutations. Routine clinical practice is challenging, left ventricular hypertrophy and HCM can be presented in different forms and different stages.

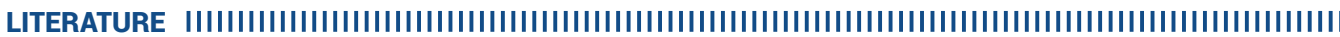

1. Kubo T, Kitaoka H. Imaging of left ventricular hypertrophy: a practical utility for differential diagnosis and assessment of disease severity. Curr Cardiol Rep. 2017 Aug;19(8):65. https://doi.org/10.1007/s11886-017-0875-5

2. Authors/Task Force members, Elliott PM, Anastasakis A, Borger MA, Borggrefe M, Cecchi F, Charron P, et al. 2014 ESC Guidelines on diagnosis and management of hypertrophic cardiomyopathy: the Task Force for the Diagnosis and Management of Hypertrophic Cardiomyopathy of the European Society of Cardiology (ESC). Eur Heart J. 2014 0ct 14;35(39):2733-79. https://doi.org/10.1093/eurheartj/ehu284

3. Maron BJ, Maron MS, Semsarian C. Genetics of hypertrophic cardiomyopathy after 20 years: clinical perspectives. J Am Coll Cardiol. 2012 Aug 21;60(8):705-15. https://doi.org/10.1016/j.jacc.2012.02.068

4. Selthofer-Relatić K. Time of Anderson-Fabry disease detection and cardiovascular presentation. Case Rep Cardiol. 2018 Mar 20:2018:6131083. https://doi.org/10.1155/2018/6131083 